\title{
Quantificação não destrutiva de clorofilas em folhas através de método colorimétrico
}

\author{
Cassandro VT do Amarante ${ }^{1,3}$; Dilson Antônio Bisognin ${ }^{2,3}$; Cristiano André Steffens ${ }^{1}$; Odimar Z \\ Zanardi $^{1,3}$; Erlani de O Alves ${ }^{1,4}$ \\ ${ }^{1}$ UDESC-CAV, C. Postal 281, 88520-000 Lages-SC; ${ }^{2}$ UFSM-Depto. Fitotecnia, Av. Roraima s/nº Camobi, $97105-900$ Santa Maria-RS; \\ ${ }^{3}$ Bolsista CNPq; ${ }^{4}$ Bolsista CAPES; amarante@cav.udesc.br
}

\begin{abstract}
RESUMO
Avaliou-se a viabilidade de utilização de um colorímetro, como alternativa à utilização de medidor de clorofila, para a quantificação não destrutiva de clorofilas em folhas. Folhas de couve 'Manteiga' e batata 'Ágata', com tonalidades variando de verde amarelado (clorótica) a verde escuro, foram avaliadas individualmente com um medidor de clorofila (Minolta SPAD-502) e um colorímetro (Minolta CR-400, no espaço de cores $L, C$ e $h^{\circ}$ ), seguido de quantificações destrutivas de clorofilas $a, b$ e totais. Os valores de leitura do medidor de clorofila e da relação $h^{\circ} /(L x C)$ do colorímetro aumentaram com o incremento nos teores de clorofilas nas folhas em couve e batata. Os modelos ajustados entre teores de clorofilas e as leituras do medidor de clorofila e da relação $h^{\circ}(L x C)$ do colorímetro apresentaram valores similares de $\mathrm{R}^{2}$, em ambas as espécies. Os resultados obtidos demonstram que o colorímetro é uma alternativa viável na avaliação não destrutiva do teor de clorofilas ( $\mu \mathrm{g} \mathrm{cm}^{-2}$ de folha), especialmente de clorofilas $a$ e totais. Para tanto, os valores da relação $h \%(L x C)$ do colorímetro devem ser calibrados com a extração de clorofilas nas folhas da espécie e genótipo de interesse.
\end{abstract}

Palavras-chave: Brassica oleracea var. acephala, Solanum tuberosum L., cor da folha, propriedades óticas da folha, absorbância, refletância.

\begin{abstract}
Non-destructive quantification of chlorophylls in leaves by means of a colorimetric method

This work was carried out to evaluate the viability of the use of a chroma meter as an alternative to the leaf chlorophyll meter for nondestructive quantification of chlorophylls in the leaves. Leaves of kale ('Manteiga') and potato ('Ágata') plants, with colors ranging from yellow-green (chlorotic) to dark green, were individually assessed with the chlorophyll meter (SPAD-502) and the chroma meter (Minolta CR-400, at the $L, C$, and $h^{\circ}$ color space), and, thereafter, destructively assessed for total chlorophyll and chlorophylls $a$ and $b$. The chlorophyll meter reading and the $h^{o} /(L x C)$ ratio for the chroma meter increased with the increment of chlorophylls content in the leaves of kale and potato. The adjusted models between chlorophylls content versus chlorophyll meter readings and the $h^{\circ} /(L x C)$ ratio for the chroma meter had similar $\mathrm{R}^{2}$ in both species. The chroma meter is a viable alternative for non-destructive assessment of chlorophylls $\left(\mu \mathrm{g} \mathrm{cm}^{-2}\right)$ in leaves, especially of chlorophyll $a$ and total chlorophyll. Nevertheless, this requires the calibration between the $h^{\circ} /(\operatorname{Lx} C)$ ratio of the chroma meter and the chlorophylls extracted from leaves of concerned specie and genotype.
\end{abstract}

Keywords: Brassica oleracea var. acephala, Solanum tuberosum L., leaf color, leaf optical properties, absorbance, reflectance.

(Recebido para publicação em 3 de dezembro de 2007; aceito em 31 de outubro de 2008) (Received in December 3, 2007; accepted in October 31, 2008)

$\mathrm{O}$ conteúdo de clorofilas nas folhas é influenciado por diversos fatores bióticos e abióticos, estando diretamente relacionado com o potencial de atividade fotossintética das plantas (Taiz \& Zeiger, 2002). Portanto, a sua quantificação é relevante no estudo de práticas culturais e de manejo visando aumentar o potencial fotossintético e de rendimento em espécies vegetais.

O método padrão de determinação de clorofilas em laboratório (Arnon, 1949), ainda que fácil, apresenta desvantagens, já que resulta na coleta destrutiva do material vegetal, e é relativamente demorado (requer tempo necessário para a extração, via maceração com acetona ou outro solvente, e posterior leitura em espectrofotômetro). Com o advento de medidores portáteis, que utilizam prin- cípios óticos não destrutivos, baseados na absorbância e/ou refletância da luz pelas folhas, a determinação de clorofilas tornou-se fácil e rápida, podendo ser realizada diretamente a campo (Richardson et al., 2002).

O equipamento Minolta SPAD-502 tem sido utilizado na quantificação de clorofilas, caracterizando-se pela rapidez, simplicidade e, principalmente, por possibilitar uma avaliação não destrutiva do tecido foliar. Para a quantificação de clorofilas, a folha é presa entre uma haste flexível e outra rígida (pressionando-se a haste flexível) no momento da medição. A haste flexível emite luz, que atravessa o tecido foliar e atinge um receptor (fotodiodo de silicone) na haste rígida, que converte a luz transmitida em sinais elétricos analógicos. Por meio do conversor A/ $\mathrm{D}$, esses sinais são amplificados e convertidos em sinais digitais, sendo usados por um microprocessador para calcular a leitura SPAD ("Soil Plant Analytical Division Value"). A intensidade de cor verde na folha é detectada no aparelho através da quantidade de luz absorvida pela folha, nos comprimento de onda $(\lambda)$ de $650 \mathrm{~nm}$ (vermelho) e 940 $\mathrm{nm}$ (vermelho distante próximo). A luz absorvida no $\lambda$ de $650 \mathrm{~nm}$ (pelas clorofilas, sem a interferência ocasionada pelos carotenóides) indica a quantidade de clorofilas, enquanto a quantidade absorvida próximo do $\lambda$ de $940 \mathrm{~nm}$ serve como referência interna na compensação da espessura e conteúdo de água da folha (Swiader \& Moore, 2002). A pequena área do sensor do equipamen- 
to $(2 \times 3 \mathrm{~mm})$ permite a sua utilização para a quantificação de clorofilas até mesmo em folhas de pequeno tamanho. Este equipamento tem sido utilizado com sucesso para diagnosticar o estado nutricional de diversas espécies hortícolas, como batata (Gil et al., 2002; Gianquinto et al., 2003; Uddling et al., 2007), tomate (Guimarães et al., 1999), pimentão (Godoy et al., 2003; Madeira et al., 2003), abóbora (Swiader \& Moore, 2002), melão (Azia \& Stewart, 2001), entre outras. Todavia, como o equipamento fornece uma leitura em unidades arbitrárias (leitura SPAD de conteúdo de clorofila, na faixa de 0 a $99,9)$, recomenda-se que o mesmo seja calibrado com as extrações de clorofilas da cultura de interesse (Markwell et al., 1995; Azia \& Stewart, 2001).

O colorímetro Minolta CR (séries 100, 200300 e 400) também pode ser utilizado para a avaliação não destrutiva da coloração de tecidos vegetais, como ocorre em frutos (Amarante et al., 2007). Este equipamento tem sensibilidade similar a do olho humano, com a vantagem de produzir a mesma leitura, independente da condição de iluminação do ambiente, já que utiliza uma fonte interna de luz e um sistema de compensação de leitura, constituído de dois sensores internos, um que mede a luz refletida da superfície do tecido vegetal e outro sensor que mede a luz da fonte de iluminação. A fonte de luz do equipamento gera radiação difusa (com diferentes ângulos de incidência), e o sensor interno recebe a luz refletida verticalmente pela superfície do tecido no espaço de cores $L, C$ e $h^{\circ}$ (McGuire, 1992). Este sistema usa o mesmo diagrama do espaço de cores $L, a$ e $b$, porém com coordenadas cilíndricas ao invés de coordenadas retangulares. Os termos $L, C$ e $h^{o}$ indicam brilho ('lightness'), cromaticidade e ângulo hue, respectivamente. Os valores de $h^{o}$ apresentam as seguintes correspondências quanto às cores da superfície do tecido vegetal: $0 \%$ vermelho, $90^{\circ} /$ amarelo, $180^{\circ}$ /verde e $270^{\circ}$ azul. Portanto, o valor de $h^{o}$ do equipamento permite quantificar o teor de clorofilas em folhas (folha verde intensa, com elevado teor de clorofila, apresentando $h^{o}$ próximo de $180^{\circ}$, e folha clorótica, com bai- xo teor de clorofila, apresentando $h^{\circ}$ próximos de $90^{\circ}$ ). Em adição ao $h^{\circ}$, os valores de $L$ permitem detectar tonalidades de verde (valores baixos correspondem a coloração verde escura e valores altos a coloração verde clara), enquanto os valores de $C$ identificam a pureza da cor (valores altos indicam maior desvio a partir do ponto correspondente ao cinza, de menor $C$ ). Todavia, este equipamento nunca foi avaliado quanto à viabilidade de utilização na quantificação não destrutiva de clorofilas em folhas, através da medição dos atributos de cor $L, C$ e $h^{o}$.

Este trabalho foi conduzido visando avaliar a viabilidade de utilização de um colorímetro, como alternativa à utilização do medidor de clorofila, para a quantificação não destrutiva dos teores de clorofilas em folhas de couve e batata.

\section{MATERIAL E MÉTODOS}

Foram coletadas 20 folhas de couve 'Manteiga' (Brassica oleracea L. var. acephala) e 16 folhas de batata 'Ágata' (Solanum tuberosum L.), cujas tonalidades variavam de verde amarelado (folha clorótica) a verde escuro. Em ambas espécies, as folhas foram coletadas cerca de 70 dias após o plantio (em 09/04/ 07 e 10/05/07 para couve e batata, respectivamente), em horta comercial localizada no município de Lages-SC. Foram utilizadas folhas totalmente expandidas, removidas do terço médio das plantas, no período entre 8-10 h da manhã (com temperatura de $15-18^{\circ} \mathrm{C}$ e umidade relativa de $75-85 \%$ ), transportando-as para o laboratório com o pecíolo imerso em água destilada para evitar a desidratação.

Em seis pontos de cada folha, em ambas as espécies, foram feitas leituras utilizando o medidor portátil de clorofila SPAD-502 e o colorímetro CR-400 (ambos da Konica Minolta ${ }^{\circledR}$, Japão), procedendo-se o cálculo da média das leituras por folha. O colorímetro CR-400 foi utilizado com ponteira de vidro côncava CR-A33f (abertura de $8 \mathrm{~mm}$ ) para a quantificação da cor no espaço de cores $L, C$ e $h^{\circ}$ (McGuire, 1992), sendo as folhas colocadas sobre superfície branca (folha de papel branco) para evitar qualquer interferência da cor desta superfície nas leituras de refletância da folha.

Em cada folha, nos mesmos pontos onde foram feitas as leituras de cor com o SPAD-502 e o colorímetro CR-400, com o auxílio de um furador de rolha, foram removidos discos $(\varnothing=1,6 \mathrm{~cm})$, nos quais foram determinados a massa fresca (com uma balança analítica, com precisão de 0,0001 g) e a área total (com um integrador de área foliar LI-COR modelo LI-3050A). Os discos de cada folha (seis) foram imediatamente macerado em acetona a $80 \%$, na presença de $\mathrm{CaCO}_{3}$, em ambiente com fonte de iluminação artificial verde de baixa intensidade. Os extratos obtidos foram filtrados através de papel-filtro rápido e coletados em balões volumétricos de 25 $\mathrm{mL}$, completando-se o volume ao final da filtragem. A densidade ótica dos filtrados foi lida em espectrofotômetro (Carl Zeiss ${ }^{\circledR}$, UV-Vis Spekol, Alemanha) nos $\lambda$ de 645 e 663 nm, utilizando cubetas de quartzo. A partir dessas leituras, determinou-se a concentração (mg $\mathrm{cm}^{-3}$ ) de clorofilas $a, b$ e totais nas soluções de leitura, por meio de fórmulas propostas por Arnon (1949):

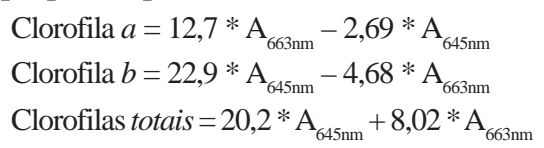

Estes valores foram transformados para teores de clorofilas $a, b$ e totais nas folhas, expressos em unidades de área $\left(\mu \mathrm{g} \mathrm{cm}^{-2}\right)$ e de massa fresca $\left(\mu \mathrm{g} \mathrm{g}^{-1}\right)$, segundo sugestão de Richardson et al. (2002).

Foram feitas análises de regressão linear e não-linear entre as leituras obtidas com o auxílio dos dois equipamentos e os teores de clorofilas $a, b$ e totais quantificados nas folhas, através da utilização do programa SAS.

\section{RESULTADOS E DISCUSSÃO}

Os valores de leitura do medidor de clorofila SPAD-502 apresentaram aumento linear em couve (Figura 1) e quadrático em batata (Figura 2), com o incremento nos teores de clorofilas $a, b$ e totais nas folhas.

Houve uma forte relação entre valores de $h^{o}, L$ e $C$ quantificados com o 


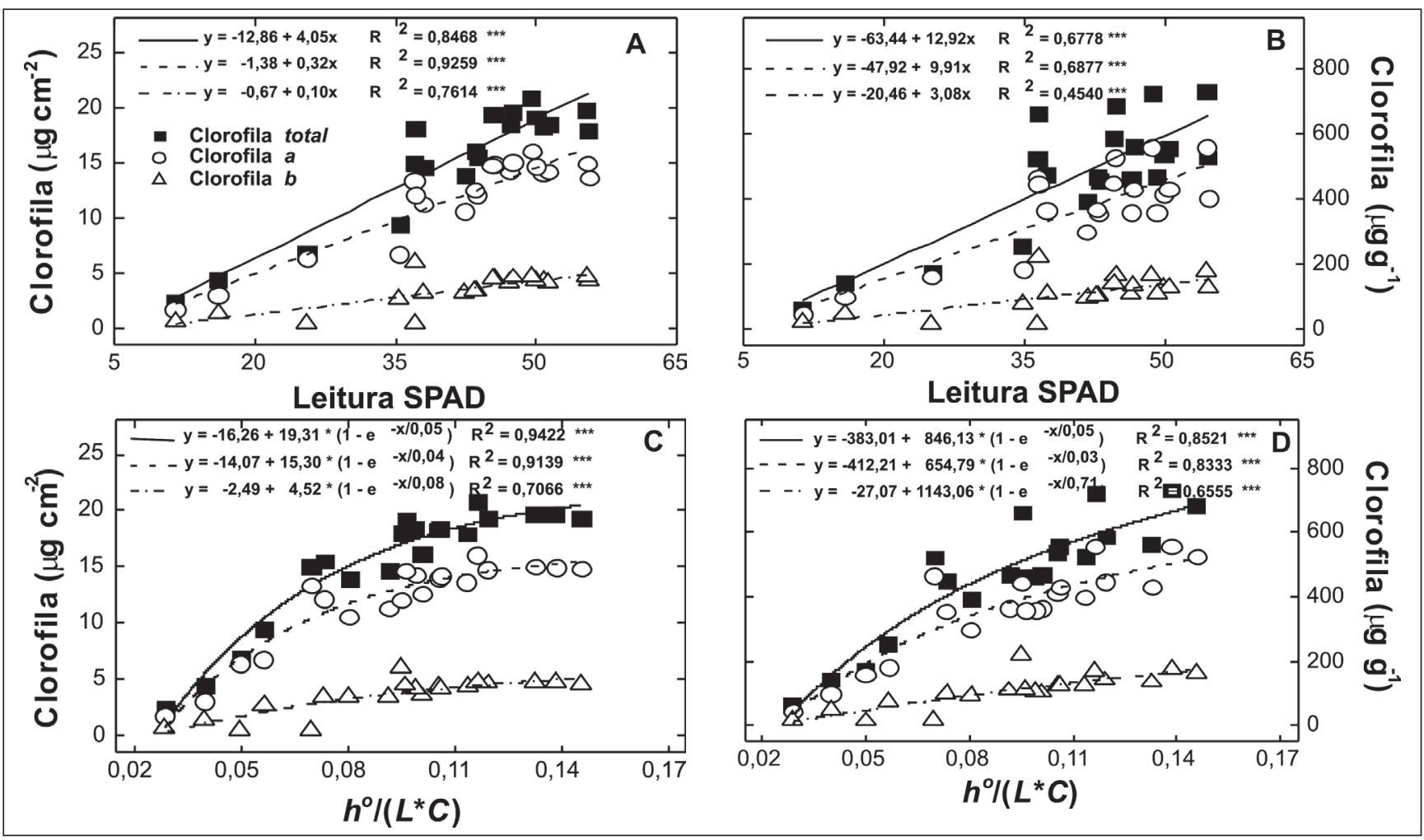

Figura 1. Relação entre valores de leitura do medidor de clorofila SPAD-502 (A e B) e $h^{\circ} /\left(L^{*} C\right)$ do colorímetro CR-400 (C e D) versus teores de clorofilas $a, b$ e totais, em unidades de área $\left(\mu \mathrm{g} \mathrm{cm}^{-2}\right)$ e de massa fresca $\left(\mu \mathrm{g} \mathrm{g}^{-1}\right)$, em folhas de couve 'manteiga' (relationship between the chlorophyll meter readings of SPAD-502 (A and B) and the $\mathrm{h}^{\circ} /(\mathrm{LxC})$ ratio of the chroma meter CR-400 (C and D) versus contents of chlorophylls $\mathrm{a}$ and $\mathrm{b}$ and total chlorophyll, expressed in units of area $\left(\mu \mathrm{g} \mathrm{cm}^{-2}\right)$ and flesh matter $\left(\mu \mathrm{g} \mathrm{g}^{-1}\right)$, in kale leaves, cv. Manteiga). CAV/UDESC, Lages, SC, 2007.

colorímetro CR-400 e os teores de clorofilas $a, b$ e totais, expressos em unidades de área $\left(\mu \mathrm{g} \mathrm{cm}^{-2}\right.$ de folha) e de massa fresca $\left(\mu \mathrm{g} \mathrm{g}^{-1}\right)$, em folhas de couve 'manteiga' e batata 'Ágata' (dados não apresentados). Houve aumento do $h^{o}$ com o incremento nos teores de clorofilas $a, b$ e totais nas folhas de couve e batata, segundo um modelo exponencial, indicando uma mudança de coloração de amarelo (folha clorótica) para verde intenso. Os valores de $L$ e $C$ reduziram com o aumento nos teores de clorofilas $a, b$ e totais nas folhas de couve e batata, indicando uma redução no brilho e na cromaticidade. Com o incremento na coloração verde houve redução exponencial de $L$ e redução linear de $C$.

A utilização da relação $h^{\circ} /(L x C)$ resultou em melhor ajuste de modelos com os teores de clorofilas $a, b$ e totais nas folhas em couve (Figura 1) e batata (Figura 2), do que a utilização individual destes atributos de cor (dados não apresentados). Com o incremento nos teores de clorofilas $a, b$ e totais nas folhas em couve (Figura 1) e batata (Figura 2), houve um aumento assintótico da relação $h^{\circ} /(L x C)$.

Apenas em folhas de couve, para os teores de clorofilas $a$ e $b$ expressos em unidades de área, os modelos lineares ajustados para os valores da leitura do medidor de clorofila SPAD-502 apresentaram maior $\mathrm{R}^{2}$ do que os modelos assintóticos ajustados para a relação $h^{\circ} /$ $(L x C)$ do colorímetro CR-400 (Figura 1). Nos demais casos, para os teores de clorofilas $a, b$ e totais em unidades de área e de massa fresca foliar, os modelos ajustados para a leitura do medidor de clorofila SPAD-502 apresentaram menores valores de $\mathrm{R}^{2}$ comparativamente aos modelos ajustados para a relação $h^{\circ} /(L x C)$ do colorímetro CR-400, em folhas de couve (Figura 1) e batata (Figura 2).

Os modelos ajustados para teores de clorofilas em unidades de área apresentaram maiores valores de $\mathrm{R}^{2}$ do que aqueles ajustados para teores de clorofilas em unidades de massa fresca, referente às clorofilas $a, b$ e totais, para a leitura do SPAD-502 e a relação $h^{\circ}$ $(L x C)$ do colorímetro CR-400, tanto em couve (Figura 1) como em batata (Figura 2). Portanto, variação que ocorre na área foliar específica $\left(\mathrm{cm}^{2} \mathrm{~g}^{-1}\right.$ de massa fresca), influenciada por diferenças entre folhas na espessura do mesófilo e conteúdo de água, resulta em maior variabilidade nos valores expressos em unidades de massa fresca foliar $\left(\mu \mathrm{g} \mathrm{g}^{-1}\right)$. Portanto, a expressão dos teores de clorofilas em unidades de área $\left(\mu \mathrm{g} \mathrm{cm}^{-2}\right)$ deve ser preferida, quando estimada através da utilização do medidor de clorofila SPAD-502 e do colorímetro CR400, já que resulta em menor erro.

Os modelos ajustados de leitura do medidor de clorofila SPAD-502 e da relação $h^{\circ} /(L x C)$ do colorímetro CR-400 apresentaram maior $\mathrm{R}^{2}$ para a estimativa dos teores de clorofilas $a$ e totais do que para a clorofila $b$, tanto em couve (Figura 1) como em batata (Figura 2). Resultados similares foram reportados por Richardson et al. (2002), trabalhando com o SPAD-502 e índices de refletância espectral em folhas de bétula 


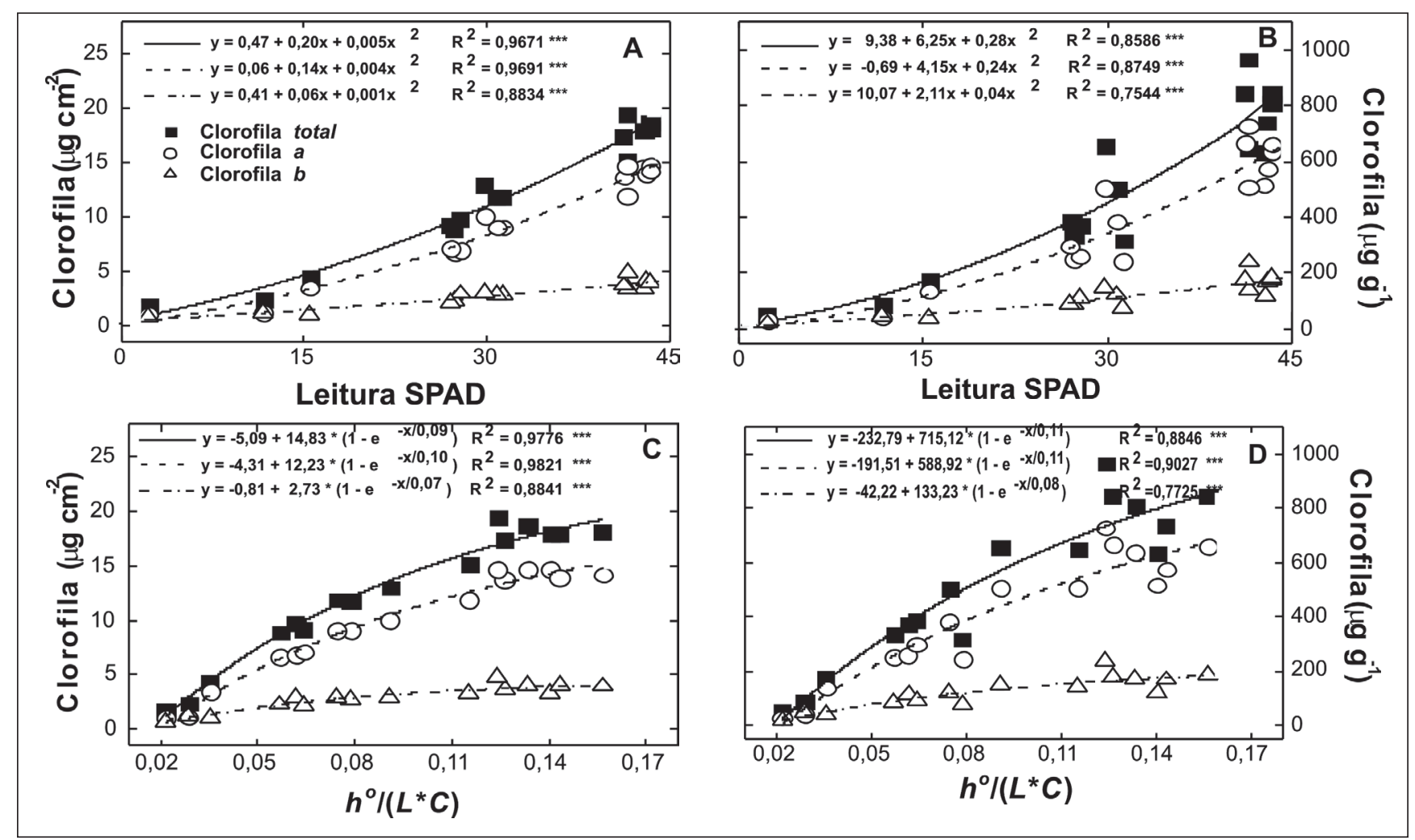

Figura 2. Relação entre valores de leitura do medidor de clorofila SPAD-502 (A e B) e $h^{o} /\left(L^{*} C\right)$ do colorímetro CR-400 (C e D) versus teores de clorofilas $a, b$ e totais, em unidades de área $\left(\mu \mathrm{g} \mathrm{cm}^{-2}\right)$ e de massa fresca $\left(\mu \mathrm{g} \mathrm{g}^{-1}\right)$, em folhas de batata 'Ágata' (relationship between the chlorophyll meter readings of SPAD-502 (A and B) and the $\mathrm{h}^{\circ}(\mathrm{LxC})$ ratio of the chroma meter CR-400 (C and D) versus contents of chlorophylls a and $\mathrm{b}$ and total chlorophyll, expressed in units of area $\left(\mu \mathrm{g} \mathrm{cm}^{-2}\right)$ and flesh matter $\left(\mu \mathrm{g} \mathrm{g}^{-1}\right)$, in potato leaves, cv. Ágata). CAV/UDESC, Lages, SC, 2007.

(Betula papyrifera Marsh.), demonstrando que a utilização de métodos não destrutivos óticos são melhores para a estimativa dos teores de clorofilas $a$ e totais do que de clorofila $b$.

Neves et al. (2005), trabalhando com o SPAD-502 em algodoeiro, também observaram maior correlação das leituras do equipamento com os teores de clorofila $a$ comparativamente a clorofila $b$. Segundo estes autores, isto ocorre tendo em vista que o pico de absorção na faixa vermelha do espectro pela clorofila $a(663 \mathrm{~nm})$, além de ser maior que o da clorofila $b$, está muito próximo do comprimento de onda emitido pelo SPAD-502 (650 nm). Com isso, a maior parte da luz vermelha, emitida pelo aparelho, é absorvida pela clorofila $a$. Portanto, em estudos que visam à calibração desse aparelho, para se obter medidas indiretas de clorofila, devem-se evitar leituras em folhas sombreadas, pois, nelas, o teor de clorofila $b$ é proporcionalmente maior do que o de clorofila $a$, quando comparadas com as folhas em pleno sol (Taiz \& Zeiger, 2002).
Tanto para a leitura do medidor de clorofila SPAD-502 como para a relação $h^{\circ} /(L x C)$ do colorímetro CR-400, houve aumento na dispersão dos dados, em relação aos modelos ajustados, com o incremento nos valores de teores de clorofilas $a, b$ e totais, em couve e batata (Figuras 1 e 2). Esta dispersão foi maior para os valores de teores expressos em unidades de massa fresca foliar, especialmente de clorofilas $a$ e totais. Portanto, a expressão quantitativa de clorofilas em unidades de massa fresca não só apresenta maior erro em relação a unidades de área, mas esse erro aumenta com o incremento nos teores de clorofilas nas folhas em couve e batata.

Como a função das clorofilas é absorver quantas de luz incidente, poderse-ia supor que a medição da quantidade de radiação absorvida pela folha com o SPAD-502 resultaria em uma melhor estimativa de clorofilas do que a medição da luz refletida pela superfície da folha, obtida com o colorímetro CR-400. Todavia, os resultados obtidos mostram que o colorímetro CR-400 é tão ou mais eficiente do que o medidor de clorofila SPAD-502, para a quantificação de clorofilas em folhas de couve e batata.

O SPAD-502, mesmo com sistema de compensação (luz absorvida no $\lambda$ de $940 \mathrm{~nm}$ ) para alterações na espessura e conteúdo de água da folha, apresenta grandes variações de leitura entre espécies de plantas (Richardson et al., 2002) e entre genótipos de uma mesma espécie (Bullock \& Anderson, 1998) cultivados em uma mesma condição de ambiente, devido a diferenças na estrutura e anatomia foliar. Mesmo um genótipo pode apresentar grandes variações no índice SPAD, ocasionadas por diferenças nas condições edafoclimáticas (Paliwal \& Karunaichamy, 1995), no conteúdo de água (Martínez \& Guiamet, 2004), estádio fenológico (Paliwal \& Karunaichamy, 1995) e posição/idade da folha na planta (Hoel \& Solhaug, 1998; Gil et al., 2002). Até mesmo o nível de radiação no momento da medição interfere na leitura do SPAD-502. Os 
cloroplastos mudam sua orientação nas células em resposta ao nível de radiação incidente. Em baixa radiação os cloroplastos orientam-se ao longo das paredes celulares superiores e inferiores, perpendicular ao sentido de incidência da luz, enquanto em alta radiação eles estão orientados principalmente ao longo das paredes verticais das células, paralelamente ao sentido de incidência da luz (Taiz \& Zeiger, 2002). Como consequiência disso, as leituras do SPAD502 são maiores quando medidas em condições de baixa luminosidade, como por exemplo no início da manhã ou ao fim da tarde, ou em folhas sombreadas da planta (Hoel \& Solhaug, 1998; Martínez \& Guiamet, 2004).

Os resultados obtidos demonstram que o colorímetro CR-400 apresenta viabilidade técnica na avaliação quantitativa não destrutiva dos teores de clorofilas $a, b$ e totais em folhas de couve e batata, em substituição ao SPAD-502, através do cálculo da relação $h^{\circ} /(\operatorname{Lx} C)$. Todavia, deve-se ressaltar que, à semelhança do que ocorre com o SPAD-502, devem ser tomados cuidados quanto à idade/posição da folha, estádio fenológico e condições no ambiente de desenvolvimento da planta a ser utilizada, procedendo-se a calibração do colorímetro com as extrações de clorofilas da espécie e genótipo de interesse. Destaca-se ainda que o colorímetro apresenta maior confiabilidade quando utilizado para a quantificação do teor de clorofilas em unidades de área $\left(\mu \mathrm{g} \mathrm{cm}^{-2}\right)$, especialmente de clorofilas $a$ e totais.

\section{AGRADECIMENTOS}

Os autores agradecem ao CNPq, à FINEP e à CAPES pelo apoio financeiro a este projeto.

\section{REFERÊNCIAS}

AMARANTE CVT; STEFFENS CA; MOTA CS; SANTOS HP. 2007. Radiação, fotossíntese, rendimento e qualidade de frutos em macieiras 'Royal Gala' cobertas com telas antigranizo. Pesquisa Agropecuária Brasileira 42: 925-931.

ARNON DI. 1949. Copper enzymes in isolated chloroplasts: polyphenoloxidases in Beta vulgaris. Plant Physiology 24: 1-15.

AZIA F; STEWART KA. 2001. Relationship between extractable chlorophyll and SPAD values in muskmelon leaves. Journal of Plant Nutrition 24: 961-966.

BULLOCK DG; ANDERSON DS. 1998. Evaluation of the Minolta SPAD - 502 chlorophyll meter for nitrogen management in corn. Journal of Plant Nutrition 21: 741-755.

GIANQUINTO G; SAMBO P; BONA S. 2003. The use of SPAD-502 chlorophyll meter for dynamically optimizing the nitrogen supply in potato crop: a methodological approach. Acta Horticulturae 607: 191-196.

GIL PT; FONTES PCR; CECON PR; FERREIRA FA. 2002. Índice SPAD para o diagnóstico do estado de nitrogênio e para o prognóstico da produtividade da batata. Horticultura Brasileira 20: 611-615.

GODOY LJG; VILLAS BÔAS RL; BÜLL LT. 2003. Utilização da medida do clorofilômetro no manejo da adubação nitrogenada em plantas de pimentão. Revista Brasileira de Ciência do Solo 27: 1049-1056.

GUIMARÃES TG; FONTES PCR; PEREIRA PRG; ALVAREZ VH; MONNERAT PH. 1999. Teores de clorofila determinados por medidor portátil e sua relação com formas de nitrogênio em folhas de tomateiro cultivado em dois tipos de solo. Bragantia 58: 209-216.
HOEL BO; SOLHAUG KA. 1998. Effect of irradiance on chlorophyll estimation with the Minolta SPAD-502 leaf chlorophyll meter. Annals of Botany 82: 389-392.

MADEIRA AC; FERREIRA A; VARENNES A; VIEIRA MI. 2003. SPAD meter versus tristimulus colorimeter to estimate chlorophyll content and leaf color in sweet pepper. Communications in Soil Science and Plant Analysis 34: 2461-2470.

MARKWELL J; OSTERMAN JC; MITCHELL JL. 1995. Calibration of the Minolta SPAD502 leaf chlorophyll meter. Journal of Photosynthesis Research 46: 467-472.

MARTÍNEZ DE; GUIAMET JJ. 2004. Distortion of the SPAD 502 chlorophyll meter readings by changes in irradiance and leaf water status. Agronomie 24: 41-46.

McGUIRE RG. 1992. Reporting of objective color measurements. HortScience 27: 1254-1255.

NEVES OSC; CARVALHO JG; MARTINS FAD; PÁDUA TRP; PINHO PJ. 2005. Uso do SPAD-502 na avaliação dos teores foliares de clorofila, nitrogênio, enxofre, ferro e manganês do algodoeiro herbáceo. Pesquisa Agropecuária Brasileira 40: 517-521.

PALIWAL K; KARUNAICHAMY KSTK. 1995. In-situ estimation of leaf chlorophyll by light transmittance in vegetable crops. Indian Journal of Agricultural Science 65: 361-362.

RICHARDSON AD; DUIGAN SP; BERLYN GP. 2002. An evaluation of noninvasive methods to estimate foliar chlorophyll content. New Phytologist 153: 185-194.

SWIADER JM; MOORE A. 2002. SPADchlorophyll response to nitrogen fertilization and evaluation of nitrogen status in dryland and irrigated pumpkins. Journal of Plant Nutrition 25: 1089-1100.

TAIZ L; ZEIGER E. 2002. Plant physiology. $3^{\mathrm{a}}$ edição. Sunderland: Sinauer Associates. 690p.

UDDLING J; GELANG-ALFREDSSON J; PIIKKI K; PLEIJEL H. 2007. Evaluating the relationship between leaf chlorophyll concentration and SPAD-502 chlorophyll meter readings. Journal Photosynthesis Research 91: 37-46. 